\title{
The mini-pterional approach and the atrophy of the temporal muscle
}

\author{
Leonardo C. Welling ${ }^{1} \cdot$ Nicollas Nunes Rabelo ${ }^{2}$ (I) Eberval G. Figueiredo ${ }^{2}$
}

Received: 31 July 2021 / Revised: 13 October 2021 / Accepted: 24 November 2021 / Published online: 26 November 2021

(c) The Author(s), under exclusive licence to Springer-Verlag GmbH Germany, part of Springer Nature 2021

We read with great interest the article entitled Comparison of postoperative temporalis muscle atrophy between the muscle-preserving pterional approach and the mini-pterional approach in the treatment of unruptured intracranial aneurysms, recently published by Tsunoda et al. [2]. We congratulate the authors for this very well-written work that presents interesting results. The authors evaluated the occurrence of temporal muscle atrophy by comparing the modified pterional craniotomy (described by the authors) with the mini-pterional craniotomy (MPT) originally described by Figueiredo et al. [1].

The mini-pterional craniotomy performed by the authors is a little different from the original MPT technique, including the size of the bone flap. In the original MPT, the craniotomy is completely located below the upper temporal line. However, this fact warrants that the frontal sinus is not violated, what may prevent post-operative infections. In addition, temporal muscle dissection was different in both groups, like interfascial in the modified pterional craniotomy and single layer in the mini-pterional. We routinely performed the interfascial dissection when carrying out the MPT approach [3, 4]. It is possible that the results of this study may have been influenced by these different methods. How could we eventually compare atrophy if the muscle was dissected in different ways?

Additionally, in our original description, we performed interfascial temporal muscle dissection with inferior and posterior retraction of the latter. Despite the controversial results of which mode of opening the temporal muscle is responsible for greater atrophy, in our opinion, the singleplane flap in MPT craniotomy may require greater coagulation of the temporal muscle base, especially in patients

Nicollas Nunes Rabelo

nicollasrabelo@hotmail.com

1 Neurological Surgery Department, State University of Ponta Grossa, Ponta Grossa, Brazil

2 Neurological Surgery Department, University of São Paulo, São Paulo, Brazil with more hypertrophied muscles, to not harm the surgical exposure and working angles.

Other point that is important to notice is how the comparison of the muscle volume was performed. It was not clear if it was made comparing CT scan or MRI, or both for each patient. Comparing volumes measured by CT with those quantified by MRI may have introduced additional bias.

Despite these remarks, we emphasize that the work was very well carried out, with an adequate context, especially concerning the possible need for a bypass that had not been previously planned.

\section{References}

1. Figueiredo EG, Deshmukh P, Nakaji P, Crusius MU, Crawford N, Spetzler RF, Preul MC (2007) The minipterional craniotomy: technical description and anatomic assessment. Oper Neurosurg 61(supp1_5):ONS256-ONS265. https://doi.org/10.1227/01.neu. 0000303978.11752.45

2. Tsunoda S, Inoue T, Ohwaki K, Akabane A, Saito N (2021) Comparison of postoperative temporalis muscle atrophy between the muscle-preserving pterional approach and the mini-pterional approach in the treatment of unruptured intracranial aneurysms. Neurosurg Rev. https://doi.org/10.1007/s10143-021-01558-6

3. Welling LC, Figueiredo EG (2018) Temporal muscle atrophy: not only the approach but the way you get it. J Plast Reconstr Aesthet Surg 71(3):445-446. https://doi.org/10.1016/j.bjps.2017.11.010

4. Welling LC, Figueiredo EG, Wen HT, Gomes MQT, Bor-SengShu E, Casarolli C, Guirado VMP, Teixeira MJ (2015) Prospective randomized study comparing clinical, functional, and aesthetic results of minipterional and classic pterional craniotomies. J Neurosurg 122(5):1012-1019. https://doi.org/10.3171/2014.11. JNS146

Publisher's note Springer Nature remains neutral with regard to jurisdictional claims in published maps and institutional affiliations. 